\title{
Absent Value and Postmodernism
}

\author{
Brian Crews \\ Universidad de Sevilla
}

At the end of the opening chapter of Martin Amis' novel, The Information, we find the first ambiguous reference to the "information" itself: "And then there is the information, which comes at night" (39). The immediate context in which we understand this is in connection with the novel's opening lines: "Cities at night, I feel, contain men who cry in their sleep and then say Nothing. It's nothing. Just sad dreams. Or something like that. . . " (9); then again at the end of the novel: "Then there is the information, which is nothing, and comes at night" (494). "Sad dreams," or "nothing," or "something like that" are obvious evasions or euphemisms and ultimately remind us of how nowadays we tend to avoid the "information," which can be associated at least initially with reality or the truth, perhaps about ourselves or even about society, but which, it seems, we set about avoiding in our waking hours. Curiously, in our contemporary society, "information" is precisely its most valued commodity, although, ironically, the information that we traffic in, the information that the media passes on to us, what we learn from internet and so on, is quite clearly divorced from this other kind of information, which is nothing, but happens to be true and wakes us up in the middle of the night. Ironically, the information of our waking hours would seem to be sidestepping the truth. If the implication is that there is one kind of information which is everything and another which is nothing; the irony of the novel depends on a basic inversion of which is which. This is just one aspect of Amis' novel, a novel about the rivalry between two novelists, about novel-writing, novel-reading, about the nature of the novel, or the state of the art, and also about how we value or judge literature. The implication, if we put these two themes together, is that just as the "information" tends to be avoided by individuals, so value judgements in literature would seem to be no longer based on any adequate concept of truth or reality, which is swept under the carpet, sidestepped or ignored. We will return later to Amis' novel, but first we ought to consider the nature of value, particularly within the context of postmodernity.

People tend to say that we attach value to something or we value it for particular reasons, reasons which do not always have something to do with the object, person, work of art or literature itself. While this is so we still tend to believe that value may still be inherent in the object or work of literature, and a good deal of theorising has gone on with regard to this, particularly in recent years. University lecturers believe that when they go into the classroom they are there to talk about "good" literature, about literature that not only he or she thinks is good, but which is generally considered of value, in other words, a classic, or a work which belongs to the canon. However, just what the canon has been and what it is now becoming is yet another area for theorising now that what ought to be included within it is a matter for reconsideration. Some critics, particularly those who are associated with 
New Historicism are involved in what might be called the redrawing of the boundaries of the canon which has to do perhaps more with the relation between literature and other social phenomena. As Greenblatt and Gunn point out:

As American higher education has become more accessible to people of different background-ethnic, racial, social, cultural, sexual, and religious - teachers of literature have found that the traditional humanistic curriculum seems less representative. This perception has aroused interest in revising and expanding the literary canon; it has also forced into the open the long-neglected questions about the assumptions on which that curriculum was based, the process by which it was created, etc. (3)

Due to a tendency to question what makes up literary interest and how it is produced there is no longer a determinate or stable selection of classics. This has led to a reconsideration of which literary forms best represent a particular period, how we ought to evaluate these works and so on. Now there is a tendency to consider literature from a variety of viewpoints, sometimes dependent on specific areas of study and even minority interests: there are new historical studies of the $17^{\text {th }}$ and $18^{\text {th }}$ centuries, of the romantics and the Victorians, modernism, postmodernism, but also feminist, gender and postcolonial studies, to name only a few. For example, we are told that the fact that women have been marginated in the past means that a new emphasis on women writers requires a reorganisation of the $18^{\text {th }}$ century canon. But is this really necessary? There is now a criticism which does just this, although, this would seem to suggest that value consists, then, in simply recovering what was perhaps previously unread, or unpublished. It certainly has little to do with the criteria with which literature is or should be judged.

Harold Bloom has considered the western canon and attempts to explain what it is that makes an author or a work canonical:

I have tried to confront greatness directly: to ask what makes the author and the works canonical. The answer, more often than not, turned out to be strangeness, a mode of originality that either cannot be assimilated or that so assimilates us that we cease to see it as strange. Walter Pater defined Romanticism as adding strangeness to beauty, but I think he characterized all canonical writing rather than the romantics as such. (3)

They have in common what he calls "uncanniness," which can be associated with what Shklovsky calls defamiliarisation, which, in turn, can be related to the idea of literariness of formalist criticism in general. However, there is a problem as it is possible for these qualities to be found in works that are not considered as great literature. Bloom goes on to cite Frank Kermode in Forms of Attention:

Canons which negate the distinction between knowledge and opinion, which are instruments of survival built to be time-proof, not reason-proof, are of course de-constructable; if people think there should not be such things, they may very well find the means to destroy them. Their defense cannot any longer be undertaken by central institutional power, they cannot any longer be compulsory, though it is hard to see how the normal operation of learned institutions, including recruitment, can manage without them. (4 my italics)

Canons are not reason proof, and hence value or defenses of a set of values are not reason proof either. Conversely, a multiplicity of opinions which have no real need to be backed 
up by reason can be quite readily accepted as valid in the current climate of confusion with regard to the nature of value. A slackening in these terms in postmodernity means sometimes that instead of identifying or defending particular values, we simply attribute value to everything. However, the point is that value is in fact becoming absent from any consideration of the work of art or literature itself, or is only arguably a feature of it . Given these circumstances, we might say on first consideration that value is not a question of absolutes but rather a question of taste, also that tastes are subject to change and that such changes usually depend on external factors, that is, that taste and therefore value are imposed or at least manipulated.

It is perhaps now a commonplace to say that the discourses of postmodernity set themselves up in opposition to authoritative discourses which are considered as no longer valid. But perhaps we can now go further and suggest that in postmodernity there are no longer any valid authoritative discourses, and that only a wide-ranging, various and continuously changing set of dissenting voices exists in our present western culture/society. We could call this a period of unbelief or scepticism, when values have been and are questioned but have not been replaced. Criticism has variously attached positive and negative values to the products of postmodernity: sometimes seeing it as valuable, sometimes as only a pretentious kind of kitsch, although there has been since the sixties and continues to be a market for this kind of product. Initially postmodernism may have had to do more with a more critical attitude towards the existing traditional and conventional forms of articulating and framing art and experience, tending to draw attention to their limitations, but often in a parodic fashion, often suggesting that these forms were all we had, but at the same time seeking possibilities for renewal and innovation, by often putting old forms to a new use. So, while postmodernism tended to foreground the existence of traditions and conventions in a critical manner it also questioned them as reliable forms of representing truth. However, because this kind of writing exists in some kind of relation to tradition and convention, it also implies the existence of criteria for value judgement inherent in the traditions and conventions themselves, although just as there was a reaction against tradition, so too are the criteria for evaluation put in doubt. These issues are related to the fact that there is no innocent form of representing reality: all reality is framed, cultural and conventional, even political; subject to economic forces as well as many others. Particular ways of seeing reality, conditioned by these forces have led to particular ways of representing it; coping with it; talking about it, and inevitably the way in which we evaluate these forms is subject to these influences.

In a time of mass culture, the mass media facilitate the propagation of the "information" which is not necessarily the truth, permitting albeit transient visions of a homogeneous universal ordered universe, that last only a day and will be replaced in the next news broadcast.We ought to be more aware but easily forget just to what extent information and the cultural codes of our time are dominated by politics and economics; this means that these forces limit and distort our vision of reality and with it even our concept of value: what is valuable is so, because of the worth that society governed by politics and economy attribute to it. For a time, postmodernism drew attention to the way in which this took place, foregrounding the manipulation of reality, of taste and of value, although now, this tends not to 
be the case. Now what we have is a variety of alternatives: alternative forms, alternative cultures, a variety of sub-cultures; in fact, there has been a kind of institutionalisation of minority taste.

It has become apparent that our understanding of reality relies heavily on values and ideologies which are essentially imposed as it were from the outside. Not long ago, it was possible and perhaps it is still possible to think in terms of inherited values, conventions and traditions, but these very traditions are and always have been imposed by politics and capital and incorporate the fallacies that modernist and later postmodernist writers have reacted against. The values, hierarchies or conventions inherent in culture are no longer passively accepted and are either questioned by the commentators of our time, authors and critics alike, or have been replaced by new minority values. The tendency is to agree that the traditional herarchies and canons are no longer acceptable although recently there have been a number of critics, like Bloom, Herrnstein Smith or Shankman, who, while aware of the contingencies of value, consider the possibility of some kind of consensus as regards the canonical as still viable. The reason for this may be that the questioning of values which has and up to a point still typifies postmodernism has given way to what can be considered an absence of values, which can be associated with what Jürgen Habermas has called the legitimation crisis of our time (Connor 8).

Paradoxically, while art and literature tend to highlight the diversity of taste in society, the media continue to represent established hierarchies and values. Just as poetics in literary criticism allow for and assimilate innovations and reactions as literary kinds evolve, we also find that politics and the media assimilate new, or minority tastes as forming part of what is still considered a unified culture. The fact is that contemporary society presents a fundamental paradox: its uniformity is summed up in diversity and its conformity is expressed in disagreement. Nowadays the tendency is simply to offer alternatives: there tends to be little sense of the absolute or universal with regard to any form of value; simply lots of alternatives to alternatives to alternatives. With this, the postmodern now means the coexistence of the incompatible in a social structure which legitimises such diversity, thus bringing about the displacement of the concept of value.

Postmodernism is, or at least used to be, about how we understand and come to terms with reality; drawing attention to the fact that we may not in fact understand reality but only forms, traditions and conventions which allow us to appreciate something which we assimilate as knowledge, meaning or simply experience. At the same time, naturally, it has to be asked how we know which forms and conventions are the right ones, the acceptable ones, and which ought not to be valued. After all, in spite of all we have said, and in spite of all the skepticism, individuals, and societies believe and think in terms of rights and wrongs: there is still a tendency to believe that there is a right way and a wrong way to see. However, there are multiple ways of seeing, and ways of representing too; a multitude of styles (you only have to think in terms of fashion) and the majority are endowed with, at least, a certain validity. Hence, how to relate, among other things, the sign and its referent, culture and economy, literature/fiction, criticism/history, high culture and mass culture, 
good taste, bad taste, appearance and reality, continues to be an issue, and solutions are merely temporary, partial or local.

To provide a little insight into this situation regarding the "postmodern condition," one place to start might be with the work of the same name by Jean-François Lyotard. He speaks of the "loss of meaning" in postmodernity, which derives from a failure to explain and legitimise the totality of experience in our time. In a period of social and cultural revision, minority groups offer their alternatives to what they believe to be a standardisation of taste. However, these alternatives have been incorporated into the norm too, or perhaps have even become it. Reality and truth are now plural and diverse, and diversity has become a source of value, even for its own sake (this sounds a bit clichéd too, "variety is the spice of life"), but there would appear to be no criteria which underlie this change, either aesthetic or moral, or at least society would seem to have lost sight of them. As Steven Connor has stated: "Postmodern society encompasses a multitude of different, incompatible language games, each with its own untransferable principles of legitimation" (32), and therefore each group embodies its own set of values.

For Lyotard, the true nature of reality is hidden under a cloak of rules, standards and values determined by capital and political power and made possible by the mass media. This has generated a fictitious simulacrum where, paradoxically, history, politics and culture embody the same attitudes of order, unity and identity as regards the nature of reality and shared values in spite of the obvious incompatabilities. The suggestion is that reality and values are the result of the acceptance or following of certain rules which are imposed by those powers that be, and one of the major aims of capitalism would seem to be to persuade the public to believe that they and the politicians share the same values. To this end, the propagation of a reality by the media with which the public can identify and feels gratified can be considered as a form of pornography which Lyotard feels has become the model for the visual and narrative arts, so that gratification as such becomes the epitomy of value in postmodernity. The mass media, then, provides a special kind of realism, and that realism does achieve a degree of consensus with regard to the relative value of what is represented. Lyotard writes:

Realism, whose only definition is that it tends to avoid the question of reality implicated in that of art, always stands somewhere between academicism and kitsch. When power assumes the name of a party, realism and its neoclassical complement triumph over the experimental avant-garde by slandering and banning it, that is provided the "correct" images, the "correct" narratives, the "correct" forms which the party requests, selects, propagates can find a public to desire them as the appropriate remedy for the anxiety and depression that public experiences. The demand for reality, that is, for unity, simplicity, communicability, etc., did not have the same intensity nor the same continuity in German society between the two world wars and in Russian society after the revolution: this provides a basis for a distinction between Nazi and Stalinist realism. (75-6)

Allen Thiher, in a similar vein, remarks:

The models that knowledge proposes as the real come in a series of ruptures, one model displacing another, and each bringing about a new world. What we take to be reality at any given moment is merely a game construct, a successful model, that succeeding and more se- 
ductive models can easily replace ... if those models can impose their rules as the criteria for a successful game. (163)

He goes on to quote Borges in his postscript to "Tlön, Uqbar, Orbis Tertius," who comments on how the symmetry that was Nazism was able to entrance the minds of men and impose its own fictitious values.

The fact is that political power or capital not only influence but dictate what is good taste and what is art or literature. It goes out of the hands of the artists themselves and even the question what is art or what is literature has become an unanswerable question, except for politicised academics, or it leads to the anything goes mass production of false or pseudoart that is kitsch. The result, to say the least is one of confusion, a lack or loss of taste and values which is made up for by a simulacrum of artistic taste and production through kitsch. Lyotard again:

By becoming kitsch, art panders to the confusion which reigns in the "taste" of the patrons. Artists [etc.] ... wallow together in the "anything goes" and the epoch is one of slackening. But this realism of the "anything goes" is in fact that of money: in the absence of aesthetic criteria, it remains possible and useful to assess the value of works of art according to the profits they yield. Such realism accommodates all tendencies, just as capitalism accommodates all needs, providing that the tendencies and needs have purchasing power. (76)

Reality is then, or rather, our idea of it, is governed by rules, taste and convention, usually imposed from the outside. If the kind of literature or art which as kitsch panders to the absence of taste of the general public in order to become a bestseller or peak viewing (and a million viewers can't be wrong), then art and literature in particular, has sought an easy way out: as a general or universal sense or even search for value or criteria has been abandoned then the parochial, the local and the marginal set up their own set of rules for establishing value with the resulting multiplicity of tastes in a variety of different markets ("oranges are not the only fruit"). These alternatives to succumbing to the globalising power of multinationals is related to the petites histoires that Lyotard mentions. In a society which is at once multiracial, multicultural and just about multi-everything else, then the alternative for the minorities is to produce their own art for their own sake, art for the minority group, and so on. Hence, incongruence and incompatability abound and it is easy to doubt regarding what is art or kitsch, what is valid (first) or valuable.

Perhaps what we now value is to accept the opposition to the dominant factor; but the fact is that the system now sponsors all the minority tastes and one possibility is to suggest that postmodernism involves the coexistence of opposing aesthetics, sets of rules and values, and this, paradoxically, in spite of the existence of a generalised tendency toward a mainstream public in all the media and most of the arts, including literature. It seems that just as political parties depend on each other to perpetuate their existence, the opposition and the government form part of the same system, so all the discourses of opposition have gradually become assimilated into a kind of vulgarization of the canon and "anything goesness." In the age of simulation to which Baudrillard refers there is not only an absence of reality in realistic representation, but it could extend to the absence of any aesthetic value in artistic production. There is a confusion of aesthetic value with material value: it is no 
longer possible to distinguish the area of economic production from that which has to do with ideology and culture. Culture now belongs to the market-place; culture has exploded into the economic sphere (Connor 50-2).

Perhaps, then, it is possible to postulate a new postmodernist model for art, literature, criticism, and value as that which is dependent on offering opposing points of view, the production of minority and marginal cultures' which come to rely on each others' existence in a new stage of the development of the oppositional discourse of unbelief. To coincide with this, there is a new kind of criticism which looks for validity in terms of allowing a voice to be heard, and without discriminating the nature of the voice, whether it is heard or not is all that matters. There is a false democracy of taste whose underlying message is that the dissenters must speak, the post-colonials must be heard, the minority groups, the new women and men, but where now does the value lie? Just as Baudrillard suggests that any antagonistic or subversive act consolidates the underlying political code of society, a curious kind of permissiveness which fails to or is unable to evaluate (because value is absent), justifies because these are voices which otherwise would remain silent.

This is also a time when the absence of criteria makes it easy to impose, change and create value, or even what we understand by reality. This is so because in postmodernity we live in a perpetual present, where standards and values are continually renewed and society is left with no real sense of identity or security. This lack of depth results in the superficial tendency towards fads, the need to be up to date with the latest trend (Jameson 125). Perhaps the significant point here is having lost touch with the past, and with tradition. That is, in a period of unbelief where the old has not been replaced by the new, there can only be this free play of, or free for all with regard to taste (a good example, once again, is fashion).

To sum up briefly, the expansion of the power of capital into the realm of the sign has led to confusion now that taste and value are dictated by power and capital as they are propagated by the media (Connor 47). Postmodernism has reacted against this situation but whereas once it criticised the absence of reality in existing forms of representation through parody, pastiche and so on, or sought through innovation to renovate those forms of representation (in search of a higher realism); the oppositional discourse of unbelief has deteriorated into a variety of discourses whose only merit is to be an alternative to what has become yet another series of realistic fallacies: postcolonial, feminist or whatever, it is the same old story from ostensibly different points of view but with no value other than that it offers an alternative. An even more pessimistic view would be to say that now there is no system of values outside the economic. In such a society, what is true is what is valuable; but if what is true is a marketable commodity then so too is value, and it is the media which provides the images or simulacrum of truth and value which supplant reality. In the mass media and advertising, the substitution of reality by wish fulfillment or other simulacra has meant that truth, or versions of the truth, and their subsequent or consequent values are just another commodity to be traded with and which can go out of fashion, become outmoded or unpopular, which means that it should be replaced, which it regularly is, by a more suitable image. Whether we seek truth or value, it is all now a question of marketing, and ultimately extraneous to the work of art or literature itself. 
In postmodernity there are only fictions (including the criteria for value judgements). One truth or one set of values can be readily replaced by another. Truth and value have become plural and different versions (petites histoires) compete with each other, each claiming its own validity. In such a situation it is impossible to be subversive any more because that is part of the system too. So in an age when values are questioned and the media trade in simulacra it is not surprising that false art or the imitation becomes an acceptable commodity. Rapidly changing trends, the upsurge and dying away of fashions which are imposed simply by the force of marketing, publicity and the media combined with this loss or disappearance of values which comes after two world wars, kitsch is ever more apparent.

Perhaps a few explanatory points are required here. Kitsch is a kind of pseudo art, the appearance and acceptance of which is a symptom of this postmodern age and leads to a fundamental problem which is whether we can distinguish between the fake and the real thing. It is also associated with popular culture, so that, "[w] hen writer $x$ or playwright $y$ begins to turn out x's and y's for his readied audiences, its kitsch" (Calinescu 223). Matei Calinescu quotes Harold Rosenberg as saying that "In the present organization of society only kitsch can have a social reason for being" due to a "slackness associated with finding an audience responsive to certain norms" (226). The ready acceptance of kitsch depends on fashions, fads and the rapid obsolescence of these makes it a major form of expendible art. It is closely related to economic development (Calinescu 226), and in the age of mass production and mass consumption (or viceversa), "value is measured directly by the demand for spurious replicas or reproductions of objects whose original aesthetic meaning consisted, or should have consisted, in being unique and therefore inimitable" (226). There is a consequent deterioration, or even loss of aesthetic standards: the number of consumers increases and mass production means a large quantity of imperfect commodities. This kind of art and literature is what Martin Amis in his novel associates with the kind of "trex," or kitsch, which is on offer to the passengers at airports, for mere consumption, to pass the time, or avoid boredom.

Nowadays, beauty, art, love, truth have become commodities. Art has lost its elitist claim to uniqueness and whereas kitsch was once thought to belong to the flea market or mean cheap imitations, this is no longer the case. Now there is a recurrence of the intentional cultivation of bad taste, kitsch and camp, like dada and surrealism, which, as Susan Sontag once remarked is "beautiful because it's awful" (Calinescu 229-30). This can be associated nowadays with other sub-cultures in this sense, like punks and so on. However, this kind of pseudo-artistic production can have a disruptive effect in another sense. What is at once thought a serious innovation in art or literature, once incorporated into kitsch, means that by mimicking the avant-garde (copying innovations), the unique and individual is turned into a gimmik. There are said to be two extremes with this surge of kitsh onto the market: authentic art is associated simply with wealth while what would previously have been considered as anything but art is endowed with aesthetic value (Calinescu 237). The significance of the phenomena in mass culture "in no way consists in what they have to say but rather in the extent to which what they say is a genersalisable statement about the pre- 
dispositions and attitudes of those consumers who in large aggregates [or smaller ones] are accepting the merchandise" (Leo Lowenthal in Calinescu 241).

All this draws attention to the fact that we have lost sight of value. So, once again, just what is value, or where does it lie. As Elder Olson reminds us: "While we speak of something as having value and so make 'value' an attribute of the thing, the value is not a discernible property of the thing itself; it is a certain relation between the thing, indeed in terms of real or supposed properties of the thing, and something further. It exists as a relationship exists and the term 'value' is a relative term"(310). He goes on: "There are no rules or laws of art; the work is, as we say, a law unto itself. Any generalisation we make about it is a generalisation and nothing more, and has its validity only because the particulars validate it" (312). Hence, "Value and the standards by which we evaluate are contingent upon what we are evaluating" (314). Very often a statement about value judgement tells us more about the perceiver than the object of perception, provides an insight into the standards or taste of an individual or even a community. Olson also considers that there are five ways to distinguish value propositions: those which are subjective-objective; which derive from emotion or reason; expert or inexpert opinion; a qualified or disqualified judge; a personal or a generally held opinion; and judgements which refer to some standard or not (315). However, it becomes clear that objectivity is an impossibility, that "[e]motion may generate true opinion as readily as reason may generate false. In the same way expert judgement may be wrong and inexpert right, the many wrong and the individual right; judgement from standard or criteria may consult the wrong standard or apply it incorrectly" (316). It seems then that "whatever the inherent value of a work, the value placed on it as an evaluation is obviously a function of something external to it, that is, the person evaluating" (316). Olson considers that of all the possible criteria for establishing a value judgement only the use of some standard can have any real relevance to value. However, if nowadays capital and politics impose the standards and even the values because they are not inherent to works of art or literature themselves, then the values will be their values, clearly manipulated and with no real relation to the particular work, its genre, convention or tradition. Marketing is therefore able to take advantage of this confusion in order to manipulate public taste.

Olson goes on to suggest that actual value must refer to the idea of some actual good and to state that "out of the experience of many like particulars we form a conception of a general projected excellence which becomes a criterion or standard, and we judge the particulars comparatively as they approximate to it" (319). But if we break with tradition, if there is skepticism or unbelief, in an eclectic culture of "petites histoires," of minority voices with marginal audiences, then we can no longer judge on these terms, criteria disappear in the perpetually-renewing-itself present of postmodernity. Moreover, as we have suggested, what is ultimately a real good is dependent on the values imposed by politics and capital at any given time, or is dependent upon the beliefs of divergent minority groups within society. In the end, Olson's search for valid criteria ultimately breaks down when he admits that "[o]ur conception of art and its values must be qualified always by the reflection that we shall never know all about them" (326). Once again, we discover that our inability to discover criteria which validate our judgements make the present confusion in taste in- 
evitable. The upshot of this is that it is possible to take advantage of this situation to supply false art, false values and establish false criteria for evaluation.

Almost inevitably, then, the debate on value continues. In his recent book, In Search of the Classic, Steven Shankman states:

In today's climate of critical opinion one answer to the question 'what is a classic?' comes readily to mind: a classic work of literature is a work that for political reasons those in power have decided to call a classic. There is some merit to this definition, for there are classics that have indeed created, or have attempted to create, a political order, and their status is in part derived from their relation to that political order. (ix)

However, Shankman does consider the possibility of coming to terms with what indeed makes a classic. Initially he considers that reading a classic confers prestige on its reader, which first suggests that the reader has to know beforehand what a classic is, and therefore is dependent on the existence of a canon. He refers to Gadamer in this respect: "The classic is what resists historical criticism because its historical dominion, that binding power of its validity that is preserved and handed down, precedes all historical reflection and continues through it" and also that it is "[s]omething retrieved from the vicissitudes of changing time and its changing taste ... [it] is the consciousness of something enduring, of significance that cannot be lost and is independent of all the circumstances of time in which we call something 'classical' a kind of timeless present that is contemporaneous with every other age" (xii). However, these statements are ultimately misleading if we consider that value is essentially contingent and is subject to changes through time. While there is a desire to believe that it is possible to consider a series of works which transcend time and respond to some idea of the universal, it should already be clear that the criteria to which such works must adhere rest largely on very shaky ground. Shankman provides a further definition, "a compelling, formally coherent and rationally defensible representation that resists being reduced either to there mere recording of material reality, on the one hand, or to the bare exemplifications of an abstract philosophical precept, on the other"(xiii), but this resistance of the canonical to be defined is perhaps the source of the problem. And it would seem that the importance of social determinants supercedes perhaps any inherent value in the art object itself. Curiously, this probably explains the tendency in literary criticism to place the emphasis on the text and interpretation while it tends to avoid evaluation. The result of this, however, is to further contribute to the loss of value at the present time. Moreover, this is not a novelty, as criticism has preferred to have less and less to do with evaluation. Wayne Shumaker quotes the French critic Shèrer as early as 1861 as saying:

Our aesthetic prefers contemplating to judging, studying to appreciation; or if it appreciates, it does so by letting the inmost sense of a work speak and reveal itself by degrees. It puts everything in its place, finds a place for everything. It has renounced the sterile procedure which consists in opposing one form of the beautiful to another, in preferring, in excluding. It has no prejudice, does not make up its mind in advance. It believes everything, likes everything, endures everything. ... It is as vast as the world, as tolerant as nature. (8)

Shumaker later quotes Richard Moulton who explains: 
In the conflict between judicial criticism and science the most important point is to note how the critic's own ideas are found to be slipping away from them. Between the Renaissance and the present day criticism, as judged by the methods actually followed by the critics, has slowly changed from the form of laying down laws to authors into the form of receiving laws from authors. (9)

There would seem to be no objectively recognisable criteria for evaluation. In the Classical period and in the Renaissance it was believed that the job of the critic was to "measure literary works against acccepted canons of aesthetic, rhetorical and moral propriety" (Shumaker 9), but there is no longer any agreement about the canon: the application of outmoded, personal, new found, but passing standards takes place, but the norm is to avoid appraisal and focus on the text; or to accept the value judgements of dogma, the bestseller lists determined by the arbiters of taste, which are now the media.

The nature of value is continually changing in this perpetual present and there is always some external influence even on personal taste. Barbara Herrnstein Smith explains that no one's literary tastes can be formed, sustained or exercised independently (9), and that various social determinants always operate on our appreciation of literary value (10-11). To illustrate this, she uses the example of anthologies:

The repeated inclusion of a particular work in anthologies of great poetry not only promotes but goes some distance toward creating the value of that work, as does its repeated appearance on reading lists or its frequent citation or quotation by professors, critics, poets, and other elders of the tribe; for all these acts have the effect of drawing the work into the orbit of attention of potential readers and, by making the work more likely to be experienced at all, they make it more likely to be experienced as valuable. In this sense, value creates value. (10)

Value, as we have already suggested, varies from one social group, in particular, minority group, to another so that it is also necessary to think in terms of communities of readers and the changing interests and other values of those communities:

Our interpretation of a work and our experience of its value are mutually dependent, and each depends upon what might be called the psychological "set" of our encounter with it: not the "setting" of the work or, in the narrow sense, its context, but rather the nature and the potency of our own assumptions, expectations, capacities, and interests with respect to it, our "prejudices," if you like, but hardly to be distinguished from our identity (or who, in fact, we are) at the time of the encounter. Moreover, all three, the interpretation, the evaluation and the set "operate and interact in the same fashion as the hermeneutic circle itself: that is simultaneously causing and validating themselves and causing and validating each other. (10-11)

Nowadays we subscribe to the value of a work independent of our personal response to it. We allow ourselves to be guided by academics, publicists and the media, so that the value of a work is not necessarily the value oneself gives to it but its value for others. Herrnstein Smith explains:

The nature and limits of the group may be implied by the context of the evaluation (for example, the set of others implied by a book review in Art News would be different from the set implied by a review in Scientific American, though the two sets might, of course, overlap) and may, in fact, be quite explicitly indicated, as in, "A fine book for children between 
the ages of 8 and 12 who have an interest in animals. If not otherwise characterized, however, that implicitly defined audience would presumably consist of people who are like ourselves in the pertinent respects, though it is perhaps worth remarking that some evaluators evidently believe that everyone is or should be like themselves in those respects. (13)

It seems then that we tend to make value judgements in terms of the expected effect or function of the work which will vary from one audience to another. The point is that "all value is radically contingent, being neither a fixed attribute, an inherent quality, or an objective property of things but, rather, an effect of multiple, continuously changing, and continuously interacting variables or to put it another way, the product of the dynamics of a system, specifically an economic system" (30). The lack of any real criteria for value judgements has led to the possibility of making false statements which refer to the intrinsic, objective, absolute, universal and transcendent when these values than with any possibly inherent quality of the work itself. While in the past to like something which is bad was a sign of bad taste it is now a sign of plurality of taste (Smith 30 ). Society has lost its sense of discrimination. Herrnstein Smith explains:

The prevailing structure of tastes and preferences within some community (and consequent illusion of a consensus based on objective value) will always be implicitly threatened or directly challenged by the divergent tastes and some subjects within the community (for example, those not yet adequately acculturated, such as the young, and others with uncultivated tastes, such as provincials and social upstarts) as well as by most subjects who are outside it or, more significantly, on its periphery and who thus have occasion to interact with its members (for example, exotic visitors, immigrants, colonials, and members of various minority or marginalized groups). Consequently, institutions of evaluative authority will be called upon repeatedly to devise arguments and procedures that validate the community's established tastes and preferences, thereby warding off barbarism and the constant apparition of an immediate collapse of standards and also justifying the exercise of their own normative authority. (40)

At the present time, there are a variety of procedures which pretend to ward off barbarism and establish some kind of normative authority, like the creation of and awarding of prizes. But curiously the marginalised and the minorities validate their own productions as we have suggested by referring to society as plural, multicultural, postcolonial, feminist, or whatever. Once again it comes down to the fact that these voices have to be heard, and, often, the only value is that they are heard.

It is also apparent nowadays that for many the classics have no great value, or are of no greater value that their own more marginal interests. This also has its interpretations:

The fact that Homer, Dante and Shakespeare do not figure significantly in the personal economics of these people, do not perform individual or social functions that gratify their interests, do not have value for them, might properly be taken as qualifying the claims of transcendent universal value made for such works. As we know, however, it is routinely taken as evidence or confirmation of the cultural deficiency or more piously, deprivation of such people (Herrnstein Smith 53)

But this is only possible if the academic voice continues to command respect. At the present time, the devaluation of the humanities, the apparent lack of utility of the arts, and so on, leads to a further devaluation of the academic voice, allowing, democratically, which 
now means, indiscriminately, the possibility of advocating in favour of all of those minorities and marginalised voices, without considering any quality or value, outside of that we have mentioned. This is made even more possible by the fact that, the ultimate question to be asked for any artistic or literary production is, is there a market for it? If it will sell is, in current terms, the "bottom line."

To further our consideration about whether it is possible to appreciate value in postmodernity perhaps we ought to return to how this dilemma is handled in Martin Amis' The Information. Here we have a case in point, where the protagonist is incapable of accepting the multitudinal success throughout the world of his literary rival. As the novel develops the protagonist's fortunes become bleaker as his "inferior" goes beyond any expected limits of sales, translations, interviews, national and international success. Although, the protagonist, Richard Tull, who is so amazed by his "friend" Gwyn Barry's success, is often ironised (of Richard, the narrator says at one point, "I quite agree. What an asshole" (132)), we tend to sympathise with him. This may mean that the reader becomes the butt of Amis' satire, but the overall impression is that Richard might have a point. Early on, the narrator of the novel remarks:

We are agreed-come on: we are agreed-about beauty in the flesh. Consensus is possible here. And in the mathematics of the universe, beauty helps tell us whether things are false or true. We can quickly agree about beauty in the heavens and in the flesh. But not everywhere. Not for instance, on the page. (15)

The different levels of irony in the novel allow us to be sceptical of many things which this narrator tells us, and, in fact, there are many discrepancies with regard to the beauty of the flesh, depending on the particular tastes of a character and so on. In fact, the "come on" remark suggests that this is also, perhaps, a piece of wishful thinking. However, it does help to clarify one of the main points of interest in the novel which is literary value, although, as the novel develops, it becomes clear that this, like any other judgement is subject to many outside influences and is probably manipulated, created, or imposed by the media. Here is an example.

During a discussion about the launch of a new literary magazine, the topic of conversation centres on how we gauge value, and how this involves a plurality of standards and has become a question of market research and targeting (with ultimately a material end). Initially those involved talk of high standards, but what value boils down to it seems, is to appeal to a particular audience. Richard Tull remonstrates: "Come on, this isn't America, where the magazine market is completely balkanized. Where, you know, they have magazines ... for the twice-divorced South Moluccan scuba diver" (28). But while Britain is not America, we have a clear reference to the way in which value is now plural, a question of diverse tastes, or even absence of tastes, dependent simply on the need to belong to a particular, usually minority, group. As the discussion continues the question comes up about whether men prefer reading men and women, women. Tull states: "Nabokov said he was frankly homosexual in his literary tastes. I don't think men and women write and read in exactly the same way. They go at it differently" (29). While this draws attention to the question of gender, and whether there is a marked distinction between the writing of a male 
or female author, it also has to do with the kind of audience one writes for: is there a global audience or will it tend to be male or female, or as the previous remark suggests, is there a racial, ethnic or any other difference involved when the writer or reader consider value. But then one voice speaks out and says: "Isn't this what literature is meant to be about? Transcending human difference?" (30). Well, perhaps that used to be the case, but it becomes apparent that writers may not simply think of readers as people (at least bestselling writers) but think more in terms of a particular market, about who the product is for, and the basic function it is supposed to perform. Here we should remember what Lyotard has said about the pornographic as being the new norm for realistic literature in general terms, and that the vindication of the dissenting voice is often the function of artistic production in minority markets. Curiously, yet another paradox in our society is that, for the very reasons we have mentioned, such particular requirements very often suit the general response.

Comments like "I don't care if people are male, female, black, white, puce or polkadotted" and Gwyn Barry's statement, "I find I never think in terms of men. In terms of women. I find I always think in terms of . . . people" (30), are also perhaps a sign of postmodernity: we are all the same but different, all the same in our difference. However, we then come to Richard Tull's significant response:

It must make you feel nice and young to say that being a man means nothing and being a woman means nothing and what matters is being a ... person. How about being a spider... . Let's imagine you're a spider, and you've just had your first serious date. You're limping away from that now, and you're looking over your shoulder and there's your girlfriend, eating one of your legs like it was a chicken drumstick. What would you say? I know. You'd say: I find I never think in terms of male spiders. Or in terms of female spiders. I find I always think in terms of ... spiders. (30-1)

This brings up the question about who the artistic or literary product is for, and if there can be a transcendence of human differences or only "little stories" for minorities. The novel, which is clearly a critique of certain trends in postmodernity would seem to suggest the latter, as the criteria for value judgements would appear to depend more and more on being politically correct, which in the end is to avoid speaking out, to avoid rather than transcend the question of difference. The basic irony in this novel is that while Tull struggles with his art form in search of the universal, the only form of representation capable of transcending human difference is "trex," the universal trex of Gwyn Barry, and those like him, the producers of kitsch, whose reason for being is peculiarly social, as it corresponds to a function generally accepted by the reading public.

Amis' novel also has something to say about this reading public. Richard Tull writes novels which, it turns out, "nobody [is] sure . . . [are] shit" (87). Whether the reader is able to determine whether or not his experimental novels in the modernist vein are of value or not, the work of this "marooned modernist" (170) is clearly contrasted with what the public wants. While, "Gwyn Barry would probably agree with Herman Melville: that the art lay in pleasing the readers," which has to do with dishing up kitsch, seen in a contemporary context, from Richard Tull's point of view, the aims of literature and its value are of a different kind: "Modernism was a brief divagation into difficulty, but Richard was still out there, in difficulty. He didn't want to please the readers. He wanted to stretch them until they 
twanged" (170). There is a clear opposition between their views: Gwyn who believes that "a million people can't be wrong," and Richard who is sure "a million people are always wrong" (105). The novel suggests that both statements are false, and the fairly explicit discussion of the problem of value continues throughout. Clearly, there has been a tendency, and there still is to look upon the complexity of literary works as part of their genius, but Amis even has something to say about that. The narrator's voice gives a clear opinion on Joyce, for example, "who was the best yet at genius novels, and even he was a drag about half the time" (170). A page later, what is universal and transcendental in postmodernity is summed up in Richard's description of the novels which have given Gwyn Barry success:

A. Gwyn's trex was loved by the world; his trex was universal.

B. The world loved trex; the world was trex. (171)

It seems that just as modernism had its day, so kitsch has now come into its own.

The Richard Tull character in the novel reflects extensively on the state of the novel and the question of value, and its continually changing nature is related to a few basic trends in what might be called taste. The first has to do with what he calls "The History of Increasing Humiliation," yet another unfinished book project, where the changing nature of literary protagonists in literature corresponds to changes in values. For Amis, in a universe which is always changing, it is impossible to speak of the universal. On the one hand he writes of "the decline in the status and virtue of literary protagonists. First gods, then demi-gods, then kings, then great warriors, great lovers, then burghers and merchants and vicars and doctors and lawyers. Then social realism: you. Then irony: me. Then maniacs and murderers, tramps, mobs, rabble, flotsam, vermin" (129). On the other, he describes the universe in similar terms: "The history of astronomy is the history of increasing humiliation. First the geocentric universe, then the heliocentric universe. Then the eccentric universe the one we're living in. Every century we get smaller. Kant figured it all out, sitting in his armchair. What's the phrase? The principle of terrestrial mediocrity" (129). This is perhaps another way of tracing the movement from some idea of the canonical and universal value to marginal value, minority taste or even the absence of any real sense of value whatsoever. However, the novel cannot avoid the inference of decadence and degeneration which is involved in this process. That is, the failed protagonist of the novel is in search of some sense of value, to transcend human difference and discover the universal. The irony which results from his failure coincides with society's failure to discover an argument to displace the kitsch or trex on the bestseller lists, the alternative to which is to target the minorities.

Amis's protagonist also has his thoughts on literary criticism and refers basically to the confusion in taste which has led to the absence of value in postmodernity. The basic conclusion is that "you cannot demonstrate, prove, establish-you cannot know if a book is good. A sentence, a line, a phrase: nobody knows. The literary philosophers of Cambridge spent a century saying otherwise and said nothing" (136). Their search for adequate criteria for value judgements also failed: "I. A. Richards reanatomized the human mind so that it might be capable of such divination. William Empsom offered a quantity theory of value: of what was ambiguous, what was complex and therefore good. Leavis said that while you 
can't judge literature, you can judge life, so for the purposes of judgement life and literature are the same! But life and literature were not the same" (136). The attempts to establish criteria for value judgement which we have described here have been equally inconclusive and in our mass culture, as Amis points out, the kind of novels people buy and read are junk novels, and junk novels are a kind of therapy, which along with pornographic realism are much more valuable to the majority, and this now sounds like utilitarianism, than to think in terms of the transcendence of human difference. Or perhaps, the ironic paradox is that what the academy once considered to be valuable is now the minority taste and what transcends human difference is the universal and mass produced kitsch that Amis refers to.

The Information is a kind of quest novel. Its protagonist searches for the truth, the universal which transcends human difference. While this was once considered to be the task of the artist, it has now become the task of publicity and marketing and while Richard Tull and perhaps the novel itself fail in their search for what is valuable, this draws attention to what is clearly universal: trex, or kitsch. However, the decision to highlight the absence of value in postmodernity is in itself, perhaps, indicative of a need to look for it. We have noticed how the critical and skeptical climate of postmodernity has led to the multiplicity of discourses of marginal literature which is self-validating, on the one hand, or the mass production and consumption of kitsch, on the other. A false democracy of taste and an obligation to be politically correct which legitimises diversity, minorities and the marginal is all well and good, but this has clearly become confused with aesthetic value. However, although this is a time of questioning, the belief that it is possible to know when something is good still persists. There is clearly a difference between the information which marketing, targeting, publicity, and the media provide in order to justify and propagate universal kitsch, or the alternative marginal product for minority tastes; and the "information" which is nothing and comes at night to tell Richard Tull his writing is trash. The implication is that we really can and really do know the difference, although it seems that our attempts to recover some criteria for value judgements are much too tentative to be able to overcome the power of politics and capital which have covered them over.

\section{WORKS CITED}

Amis, Martin. The Information. London: Flamingo, 1996.

Bloom, Harold. The Western Canon: the Books and School of the Ages. London: Papermac, 1995.

Calinescu, Matei. Five Faces of Modernity. Durham: Duke UP, 1987.

Connor, Steven. Postmodern Culture. An Introduction to Theories of the Contemporary. Oxford and New York: Blackwell, 1989.

Greenblatt, Stephen and Giles Gunn, eds. Redrawing the Boundaries: The Transformation of English and American Literary Studies. New York: M.L.A., 1992. 
Herrnstein Smith, Barbara. Contingencies of Value. Alternative Perspectives for Critical Theory. Cambridge. Mass.: Harvard UP, 1988.

Jameson, Frederic. "Postmodernism and Consumer Society." The Anti-Aesthetic: Essays on Postmodern Culture. Ed. Hal Foster. Port Townsend, Wash.: Bay Press, 1983: 111-125.

Lyotard, Jean Francois. The Postmodern Condition. A Report on Knowledge. Trans. Geoff. Bennington and Brian Massumi. Manchester: Manchester UP, 1984.

_. "Answering the Question: What is Postmodernism." Trans. Régis Durand. Lyotard 1984: 71-82.

Olsen, Elder. On Value Judgements in the Arts and Other Essays. Chicago and London: U of Chicago P, 1976.

Shankman, Steven. In Search of the Classic. Reconsidering the Greco-Roman Tradition, Homer to Valery and Beyond. University Park: Pennsylvania State UP, 1994.

Shumaker, Wayne. Elements of Critical Theory. Berkeley \& Los Angeles: U of California P, 1952.

Thiher, Allen. Words in Reflection: Modern Language Theory and Postmodern Fiction. Chicago: U of Chicago P, 1984. 
